\title{
RIVERBED EVOLUTION OF UPPER PART OF YANGTZE ESTUARY AND ITS RESPONSE TO THE HYDRODYNAMIC CHANGES AT UPSTREAM
}

\begin{abstract}
Yongping Chen ${ }^{1}$, Ninglin Jiang ${ }^{2}$ and Changkuan Zhang ${ }^{3}$
The riverbed evolution of upper part of Yangtze estuary, Chengtong reach, is analyzed by comparison of 6 sets of bathymetry data during 1977 2011. The significant changes of water depth profiles along 6 representative crosssections indicate this reach is still in the process of development. In order to get a better understanding of the effect of river discharge at upstream on the riverbed evolution of Chengtong reach, a series of numerical experiments are implemented by specifying different river discharge conditions at the upper boundary. The corresponding discharge ratios of main and secondary channels at 3 main sub-reaches are compared. The results show that with the increase of river discharge, the discharge ratio in the main channels of Fujiangsha sub-reach and Rugaosha sub-reach increases, but it changes to decrease when the upstream river discharge becomes very large; however, the discharge ratio in the main channel of Tongzhousha sub-reach always decreases with the increase of river discharge at upstream. The discharge ratio of secondary channel has an adverse tendency.
\end{abstract}

Keywords: Yangtze estuary; Chengtong reach; riverbed evolution; numerical modeling; upstream discharge

\section{INTRODUCTION}

Yangtze River is the longest river in China and the third longest river in the world. The estuary of Yangtze River starts from Ebizui of Jiangsu Province and reaches the East China Sea by the city of Shanghai. In recent years, the riverbed of Yangtze estuary has exhibited significant changes under the effects of natural evolution and anthropogenic works (Yang et al, 2006; Liu et al, 2007). A lot of research on the riverbed evolution of the Yangtze Estuary has been done in the past (e.g. Wang et al, 2008; Jiang et al, 2011), but most of the work focused on the field data analysis and presented the qualitative trend of riverbed evolution only.

This study combines the methods of field data analysis and numerical model simulation to analyze the riverbed evolution of the estuary and its response to the changes of upstream hydrodynamic conditions, aiming to obtain a better understanding of the quantitative relations between the riverbed evolution and the upstream hydrodynamic conditions, so as to provide a more reliable basis for prediction of the riverbed evolution.

The study area for this paper is the Chengtong reach, which is located at the upper part of the Yangtze Estuary, starting from Ebizui and ending at Xulijing, with the total length of about 90km. The cities of Jingjiang, Rugao and Nantong locate on the left bank and the cities of Zhangjiagang and Changshu locate on the right bank. The whole river regime of Chengtong reach is shown in Fig.1.

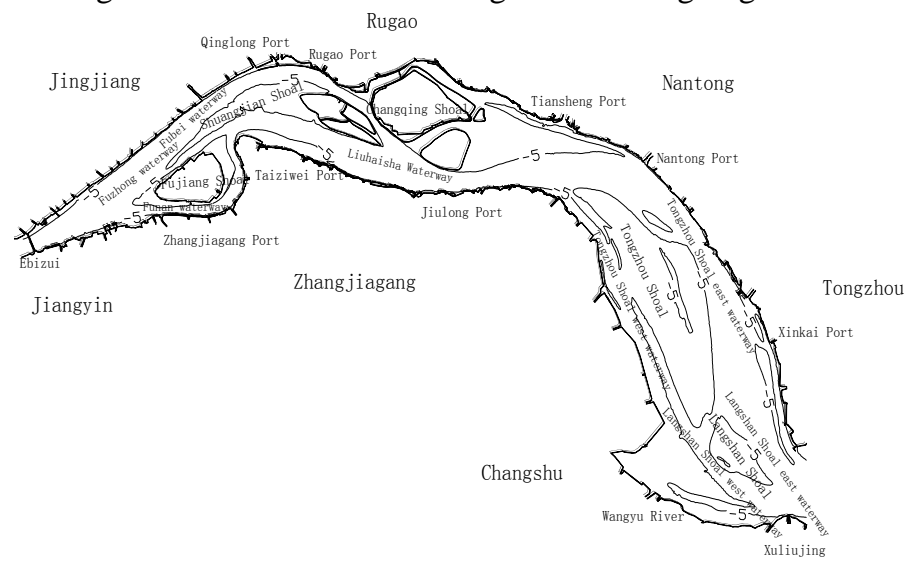

Figure 1. River regime of Chengtong reach

\footnotetext{
${ }^{1}$ State Key of Laboratory of Hydrology-Water Resources and Hydraulic Engineering, Hohai University, Nanjing, Jiangsu, 210098, China

${ }^{2}$ College of Harbor, Coastal and Offshore Engineering, Hohai University, Nanjing, Jiangsu, 210098, China

${ }^{3}$ College of Harbor, Coastal and Offshore Engineering, Hohai University, Nanjing, Jiangsu, 210098, China
} 


\section{ANALYSIS OF RIVERBED EVOLUTION}

In recent years, with the continuous implementation of bank reinforcement engineering, the bank of Chengtong reach tends to be stabilized. However, the main channels of Chengtong reach, which are connected with the Fuzhong waterway, the Liuhaisha waterway and the Tongzhousha East waterway, are not very stable because a lot of shoals exist in this reach and most of the shoals such as Fujiangsha, Rugaosha, Tongzhousha and Langshansha change quite frequently. The constant development of the shoals has caused the notable changing of erosion-siltation variation of the riverbed and the frequent swinging of deep trough in the main channels. Those are clearly shown in the changes of the talweg during 1977 2011, as illustrated in Fig. 2

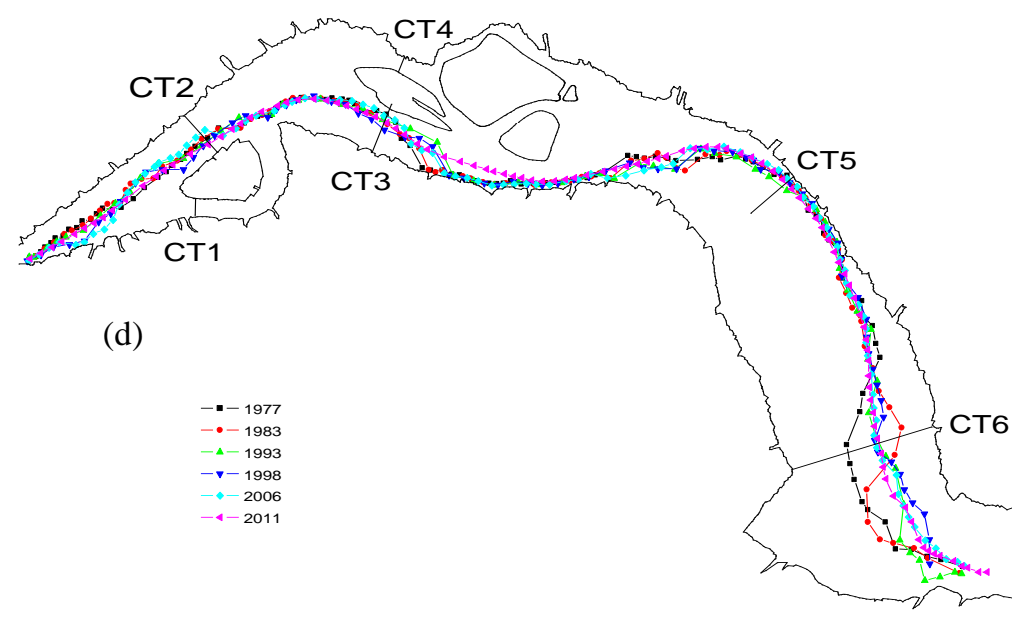

Figure 2. Changes of the talweg of Chengtong reach during 1977 2011

For a further analysis of riverbed evolution along the reach, the water depth profiles along 6 representative cross-sections, of which locations are shown in Fig. 2, are compared and shown in the following figures, i.e. Fig. 3(a) Fig. 3(f).

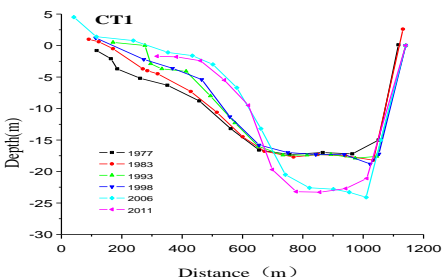

(a)

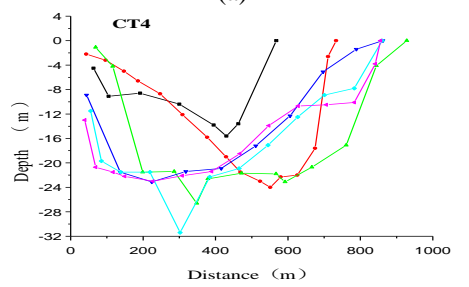

(d)

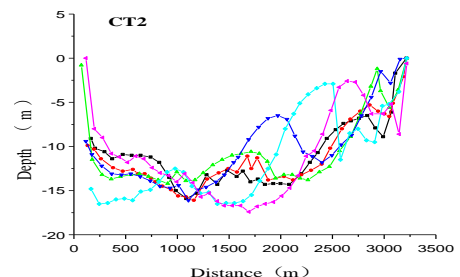

(b)

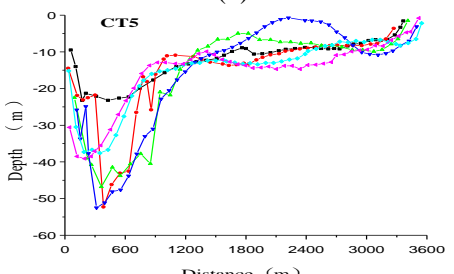

(e)

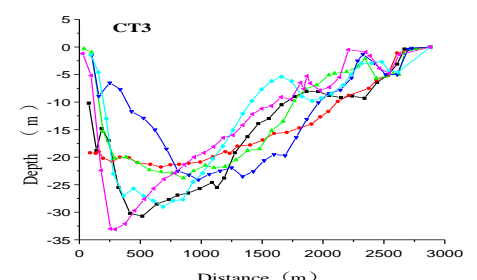

(c)

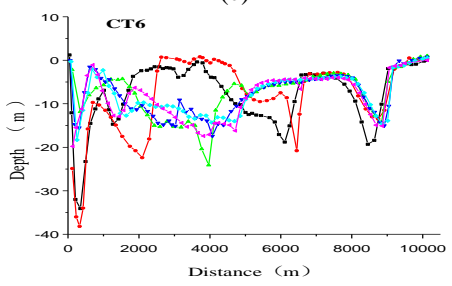

(f)

Figure 3. Changes of water depth profiles along 6 representative cross-sections

From the above figures, we can see that:

CT1 is the cross section at the Funan waterway, the main navigation channel for the city of Zhangjiagang. The Funan waterway is in the process of slow siltation from 1977 to 1998, while the waterway changes to the process of erosion from 1988 to 2011, with the water depth at the trough increases about 4 meters. 
CT2 is the cross section at the Fuzhong and the Fubei waterway. About 1,000 meters from the starting point is the place where the Fubei waterway is located. The riverbed of Fubei waterway is in the process of siltation from 1977 to 1993, but from 1993 to 2011, there is a certain amount of erosion. The Fuzhong waterway is located at the place about 2,000 meters from the starting point. From 1977 to 1993, the siltation occurs in the Fuzhong waterway but the rate is not significant. From 1998 to 2011, the Fuzhong waterway changes remarkably: firstly, significant siltation occurs in this waterway and the deep trough swings south about 500 meters; secondly, significant erosion occurs from 2006 to 2011 and the river trough moves towards north continuously.

CT3 is the cross section at the Ruyou waterway. About 1,000 meters from the starting point is the place where the deep trough is located. From 1977 to 1983, siltation occurs in this waterway and the average water level decreases about 5 meters. From 1993, the deep trough of this waterway starts scouring and the location turns to swing to and fro. It swings to south about 250 meters from 1993 to 1998 and swings to north about 600 meters from 1998 to 2011. The sectional area of this cross-section keeps decreasing from 1977 to 1998 and changes to increase from 1998 to 2011.

CT4 is the section at the Ruzhong waterway. The change of this section is quite significant during the period. The water depth is quite small and the width is relatively narrow in 1977, but the deepest water depth is over 22 meters and the width increases about 150 meters in 1983. From 1983 to 1993, the trough of this waterway begins to swing to the north and the swinging distance is about 200 meters. From 1998 to 2011 the section appears to be relatively stable.

CT5 is the section at the Tongzhousha east waterway. The deep trough of this section near the left bank is in the process of erosion during the latest thirty years and the deepest water depth increases about 30 meters from 1977 to 2011. The whole area of this section increases from 1977 to 1993, decreases from 1993 to 2006 and then increases again from 2006 to 2011.

CT6 is the section at the Langshansha. About 500 meters from the starting point is the place where the Langshansha east waterway is located and about 6,000 meters from the starting point is the place where the Langshansha west waterway is located. The Langshan shoal swings west continuously from 1983 and the Langshansha east waterway develops quickly, therefore the Langshansha east waterway gradually replaces the Langshansha west waterway as a main channel. In this period, The Langshanshatea east waterway and the Langshansha west waterway swing west continuously, with the swing distance over 2,000 meters.

\section{NUMERICAL MODEL}

In order to obtain a better understanding of the effect of river discharge at upstream on the riverbed evolution, a series of numerical experiments are implemented by specifying different river discharge conditions at upper boundary. In this study, MIKE $21 \mathrm{HD}$ model is used to carry out the numerical study. The numerical model is briefly introduced as follows.

\section{Control Equations}

The hydrodynamic model of MIKE21 is established based on the 2-D incompressible shallow water equation. The 2D depth-averaged shallow water equation is established by the integration of continuity equation (Eq. 1) and the horizontal momentum equations (Eqs. 2 and 3):

$$
\begin{aligned}
& \frac{\partial h}{\partial t}+\frac{\partial h \bar{u}}{\partial x}+\frac{\partial h \bar{v}}{\partial y}=0 \\
& \frac{\partial h \bar{u}}{\partial t}+\frac{\partial h \bar{u}^{2}}{\partial x}+\frac{\partial h \bar{v} \bar{u}}{\partial y}=f \bar{v} h-g h \frac{\partial \eta}{\partial x}-\frac{\tau_{b x}}{\rho_{0}}+\frac{\partial}{\partial x}\left(h T_{x x}\right)+\frac{\partial}{\partial y}\left(h T_{x y}\right) \\
& \frac{\partial h \bar{v}}{\partial t}+\frac{\partial h \bar{u} \bar{v}}{\partial x}+\frac{\partial h \bar{v}^{2}}{\partial y}=-f \bar{u} h-g h \frac{\partial \eta}{\partial y}-\frac{\tau_{b y}}{\rho_{0}}+\frac{\partial}{\partial x}\left(h T_{x y}\right)+\frac{\partial}{\partial y}\left(h T_{y y}\right)
\end{aligned}
$$

where $t$ is the time; $x, y$ are the Cartesian coordinates; $\eta$ is the elevation of tide surface; $h=d+\eta$ is the total depth; $d$ is the still water depth; $u$ and $v$ are the depth-averaged velocity components in $x$ and $y$ direction, respectively; $f$ is the coefficient of Coriolis force; $\rho_{0}$ is the density of water; $T_{i j}$ denotes the lateral stress of water particles, including the viscous friction force, the turbulent friction force and the convective force etc; $\tau_{b x}$ and $\tau_{b y}$ are the components of the bottom friction in $x$ and $y$ direction respectively. 


\section{Computational Parameters}

The roughness coefficient reflects the interaction between the flow and the riverbed and plays a key role in the convection process of flow field. In this study, the value of roughness ranges from 0.017 to 0.020 , varying with the geographic locations. The value of roughness in the upstream is slightly higher than the one in the downstream.

The type of computational grid is the non-structured triangular grid with the minimum scale of the grid about 200 meters. The total number of the computational grid is about 44,500.

\section{Model Verification}

The model is validated by comparison of both water level and tidal currents for spring, intermediate and neap tides, of which part results are shown in Fig. 4. Based on the good validation results, the confidence is built up to use this model to investigate the dynamic relations between the riverbed evolution and hydrodynamic conditions at upstream.

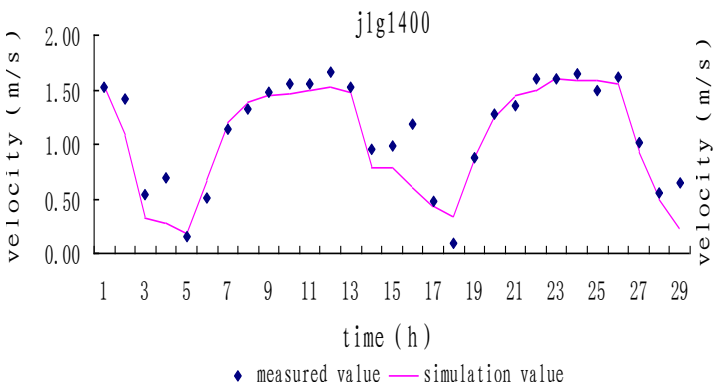

- measured value — simulation value

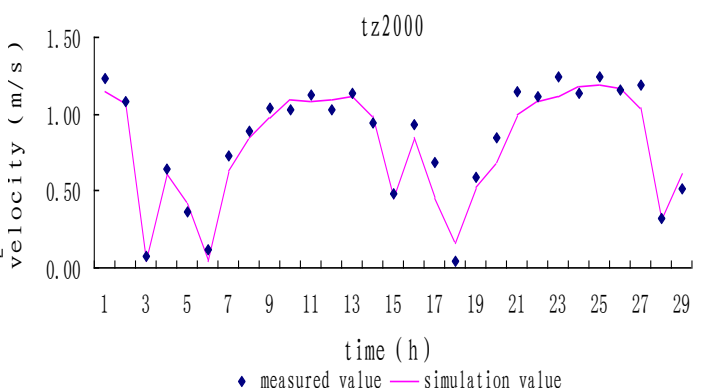

- measured value — simulation value

Figure 4. Model validation for the spring tides at two field measurement stations

\section{Upstream Discharge \& Discharge Ratio}

Under the assumption of no significant changes of bathymetry conditions, the river discharge at the up boundary can be artificially changed to study the effect of upstream hydrodynamic conditions on the riverbed evolution. In this study, 6 different discharges, i.e. $6995 \mathrm{~m}^{3} / \mathrm{s}, 8553 \mathrm{~m}^{3} / \mathrm{s}, 12380 \mathrm{~m}^{3} / \mathrm{s}$, $74400 \mathrm{~m}^{3} / \mathrm{s}, 56800 \mathrm{~m}^{3} / \mathrm{s}, 45100 \mathrm{~m}^{3} / \mathrm{s}$, which represent $90 \%, 50 \%$ and $10 \%$ of cumulative frequency of annual minimum discharge and $10 \%, 50 \%$ and $90 \%$ of the cumulative frequency of annual maximum discharge are chosen as those representative upstream discharges for the numerical investigation.

As we know, the discharge ratio is an important index to reflect the channel evolution for a longterm viewpoint. In this study, the discharge ratio is calculated by the division of the tide volume in each reach (either main or sub channels) to the total tide volume at the corresponding section.

\section{NUMERICAL RESULTS}

The corresponding discharge ratios of main and secondary channels at three main sub-reaches, i.e. Fujiangsha sub-reach, Rugaosha sub-reach and Tongzhousha sub-reach under those upstream discharge conditions are shown in Fig.5, Fig.6 and Fig. 7, respectively.

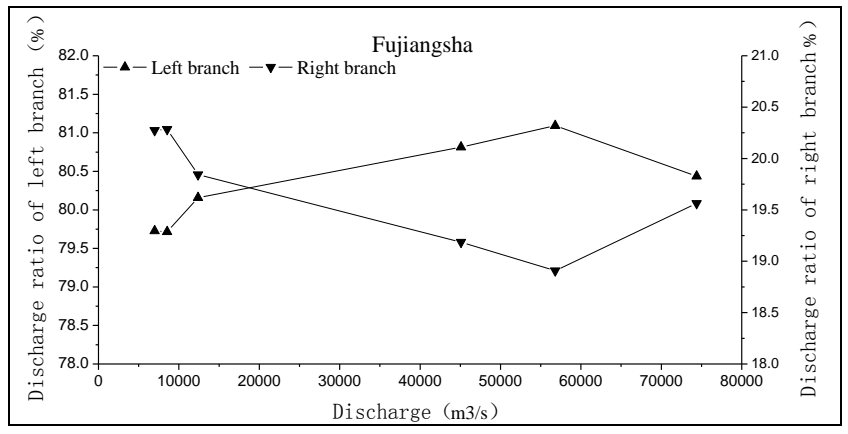

Figure 5. Discharge ratio of Fujiangsha sub-reach 


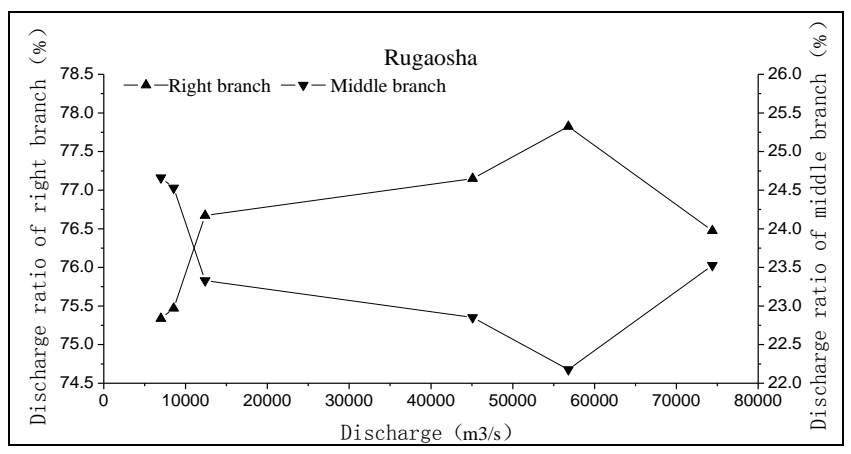

Figure 6. Discharge ratio of Rugaosha sub-reach

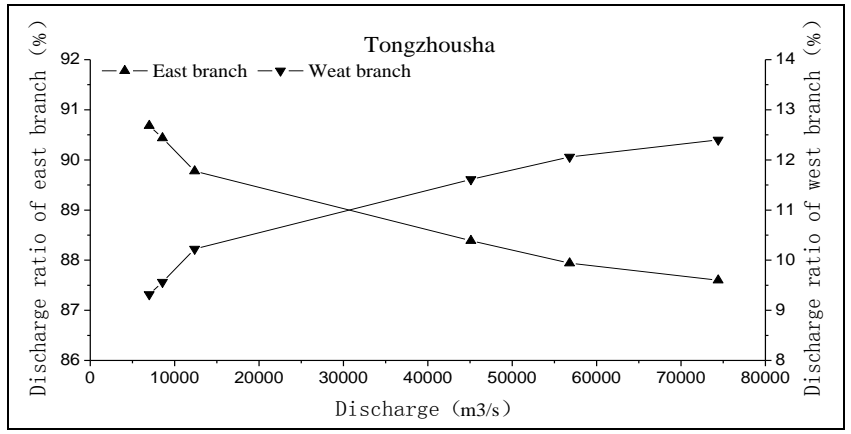

Figure 7. Discharge ratio of Tongzhousha sub-reach

From those figures, we can see that:

Fujiangsha sub-reach: With the increase of upstream discharge, the discharge ratio of Fujiangsha right branch (secondary channel, CT1 cross-section) shows a trend of decrease, while the discharge ratio of Fujiangsha left branch (main channel, CT2 cross-section) decreases accordingly. However, with the further increase of upstream discharge, the discharge ratio of main channel decreases instead, which indicates that the flooding conditions may play a negative effect on the development of main channel. In fact, this trend is mainly related to the shape of the secondary channel. In this reach, as the bottom of secondary channel is relatively narrow (see Fig. 3(a)), with the increase of upstream discharge, the increase speed of discharge in the secondary channel is relatively slow and thus the discharge ratio in the secondary channel decreases; however, with further increase of the river discharge, the significant increase of overbank flow results in a quick increase of discharge in the secondary channel and thus the discharge ratio in the main channel decreases.

Rugaosha reach: With the increase of discharge upstream, the discharge ratio of Rugaosha right branch (main channel, CT3 cross-section) increases, but the discharge ratio of Rugaosha middle branch (secondary channel, CT4 cross-section) decreases. As the boundary of the middle branch is almost stabilized due to the implementation of bank projects, the width of the middle branch remains relatively stable. In the dry season, the main flow moves to the trough of the middle channel, which causes the discharge ratio of middle reach is relatively large; however, in the flood season, because of the restraint of the limit boundary, most of the water flows to the right reach, so the discharge ratio of middle reach decreases. However, with the further increase of discharge, the water level rises and the shoal on both sides of the middle branch is flooded, the sectional area of the middle branch increases and then the discharge ratio of the main channel decreases again.

Tongzhousha reach: The water depth of Tongzhousha east branch (main channel, part of CT5 cross-section) is deeper than that of Tongzhousha west branch (secondary channel, part of CT5 crosssection). The phenomenon that water gathers in the deep channel is obvious in the dry season, so the discharge ratio of main channel is larger in the dry season; while in the flood season, the sectional area of secondary channel increases obviously, so the discharge ratio of west branch is relatively larger in the flood season. It can be seen from Fig. 7 that when the discharge increases from $6995 \mathrm{~m}^{3} / \mathrm{s}$ to $74400 \mathrm{~m}^{3} / \mathrm{s}$, the discharge ratio of main channel decreases about $3.08 \%$, which indicates that the 
increase of discharge may play a positive effect on the development of the secondary channel, but not to the main channel.

\section{CONCLUSIONS}

The riverbed evolution of upper part of Yangtze estuary, i.e. Chengtong reach, is analyzed based on the comparison of 6 sets of bathymetry during 1977 2011. A 2D numerical model is then developed to explain the response of the riverbed evolution to the hydrodynamic changes at upstream. The results show that the discharge ratio of main channels at Fujiangsha and Rugaosha sub-reaches increases first and then decreases with the increase of upstream discharge, while the discharge ratio of main channel at Tongzhousha sub-reach always decreases with the increase of upstream discharge. The reasons of the response are briefly explained in the main context.

\section{ACKNOWLEDGEMENTS}

This work was partly supported by the National Key Basic Research Program of Ministry of Science and Technology of China (2010CB429001) and the Ministry of Water Resources' Special Funds for Scientific Research on Public Welfares (201201045)

\section{REFERENCES}

Jiang, C., Li, J. and Swart, H. E. 2011. Effects of navigational works on morphological changes in the bar area of the Yangtze Estuary. Geomorphology, 139-140, 205-219

Jiang, N., Chen, Y. and Fei, X. 2011. Analyses of riverbed evolution of Chengtong reach of the Yangtze River. Port \& Waterway Engineering, 12, 112-115. (in Chinese)

Liu, J., Chen, J. and Xu, Z. 2007. Morphological Evolution and Its Response to the Navigational Improvements in the North Passage, Yangtze Estuary. China Ocean Engineering, 21(4), 611-624.

Wang, Y., Peter, V. and Wu, H. 2008. Long-term morphodynamic evolution and the equilibrium mechanism of a flood channel in the Yangtze Estuary. Geomorphology, 99(1-4), 130-138.

Yang, S., Zhao, Q. and Belkin, I. 2002. Temporal variation in the sediment load of the Yangtze River and the influences of human activities. Journal of Hydrology, 263, 56-71.

Yang, Z., Wang, H. and Saito, Y. 2006. Dam impacts on the Changjiang (Yangtze) River sediment discharge to the sea: The past 55 years and after the Three Gorges Dam. Water Resource Research, 42(4), W04407, doi:10.1029/2005WR003970. 